\title{
Germany's new old way
}

\author{
Freshly re-elected, there seem to be few radical changes ahead for Angela Merkel's government. Her \\ politics have been successful, but will Germany's neighbours start to benefit too?
}

All seems to be going well for Germany at the moment. Exports are booming, the unemployment rate is as low as it has ever been in the past twenty years ${ }^{1}$, and politically it remains one of the key players on the international stage, particularly in Europe. So perhaps it was not much of a surprise that in the elections of September 2013, Angela Merkel's Christian Democratic Union came out the clear winner with a majority not seen since the 1980s when Helmut Kohl was Chancellor.

Germany's well-being has always been tied into that of its neighbours. The majority of Germany's exports go into the European Union, yet because of the relative weakness of the Euro, exports outside the EU are more competitive. Obviously, the Euro is weaker than the Deutschmark would be, made worse because of the more troubled economic situation in other European states. This makes German exports look better. Internationally, there has of course been a lot of criticism about this situation, even from allies such as the United States, also because despite the strong exports, consumption in Germany - and thus import of goods into the country remains weak.

However, Germany's new government will have a few home-made problems to tackle. An ageing population increasingly relies on a dwindling number of young, educated workers. The country's birth rate is the lowest in Europe. A lot of the infrastructure is in urgent need of investments, from rail to the famous autobahns. And after the decision to stop all nuclear reactors, considerable investments in the power grid await.

Disagreement related to these challenges has been one of the reasons why, following the election, the formation of the new government has taken more than two months. And then, there is a new political direction. Merkel's previous coalition partner, the Liberals, have had such a weak showing that for the first time since 1949 they are not represented in the new Bundestag. Instead, Merkel now has to form a cabinet along with her old enemy, the Social Democrats. Overcoming political differences has been difficult, but now a coalition has been agreed on (with not much change in the broader political direction). The new government can rely on almost $80 \%$ of the seats in parliament, effectively dwarfing all political opposition.

In addition to the usual political gestures, the coalition agreement between the two parties also presents some forwardlooking programmes. As outlined in more detail in a leaked draft of a preliminary coalition agreement ${ }^{2}$, innovation, science and economic growth will be some of the priorities of the new government. Here, Germany will continue to invest in the future, which is in notable contrast to cuts in research budgets in countries such as the UK. Criticism has it that many political initiatives that will mainly benefit the elderly put too much burden on a shrinking younger generation.

In terms of science policy, the plans for the next government largely continue existing initiatives but also include better funding of universities, in particular those that are part of the 'excellence initiative's. There is also good news for post docs, who can expect more stability within the academic career path by the introduction of more long-term contracts. This will also benefit foreign researchers, as the new government aims to increase the number of foreign researchers, in addition to encouraging German students to gain experience abroad. Moreover, more focus will be given to achieving a better gender equality in academic careers. In terms of research funding, the key areas will remain on health as well as on energy-related research. Another major topic is more general improvements to education, with a focus on computer security and broader computer literacy.

Obviously, Europe will still be a main focus of German policy, and both coalition partners are strong advocates of largely continuing Germany's foreign policy. But what Germany needs is a healthy European economic environment, otherwise it won't be sustainable to run large budget deficits on the back of a weak Euro that mainly gives an advantage to Europe's strong economies. Germany of course believes that stern fiscal measures elsewhere will solve the problem, but whether years of austerity really will improve the situation remains to be seen.

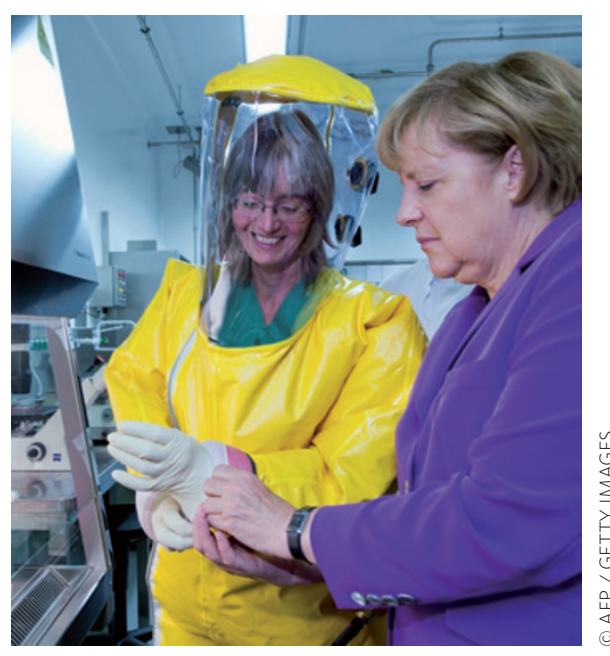

Angela Merkel on a visit to the Friedrich Loeffler Federal Research Institute for Animal Health near Greifswald in Eastern Germany.

One can only hope that, with its broad majority, the new government will be able to take decisions that may be inconvenient at home, but that will be in the long-term interest of Europe. Economic and political progress is not insular, and Merkel knows this too well. But whether she can convince her electorate to look beyond the national fence is doubtful, and the willingness for broader international collaboration remains weak. Certainly when it comes to Germany's beloved autobahns: earlier plans to introduce a road toll for the motorways which would be reimbursed to German drivers via their car tax, but not to other Europeans - seem to have hit a broad popular resonance.

Such insular thinking won't do Germany much good. Germany needs to give if it wants to do more business. In the meantime, Germany's neighbours would do well to look at some of the more forward-looking plans of the new government and its clear and unambiguous focus on scientific and technological progress.

\footnotetext{
References

1. http://go.nature.com/yUfulV

2. http://go.nature.com/jHwPLW

3. Nature Mater. 4, 795 (2005).
} 